\title{
Multi-Basis Wavenet-Based Stator Resistance Identification in DTC Induction Motor Systems
}

\author{
Jassim M. Abdul-Jabbar \\ Computer Engineering Department, University of Mosul
}

\begin{abstract}
The performance of direct torque controlled (DTC) induction motor system is greatly affected by the change of the motor stator resistance especially when the motor runs at low speeds. A new architecture of multi-basis wavenet-based model is proposed and implemented for stator resistance identification. Such multi-basis model utilizes multi-set daughter wavelets. By means of enough training of samples, the descent gradient algorithm is used to fulfill both system structure and parameters initialization, and the stator resistance is then acquired online with the operation of the system. The simulation results were carried out using Matlab/Simulink library and compared with those obtained from classical stator resistance identification method based on PI control and from another recent wavenet-based method. The simulation results show that the proposed method can improve the system performance.
\end{abstract}

Keywords: Wavenet, Multi-basis wavenet, Direct torque control, Stator resistance, Induction motor.

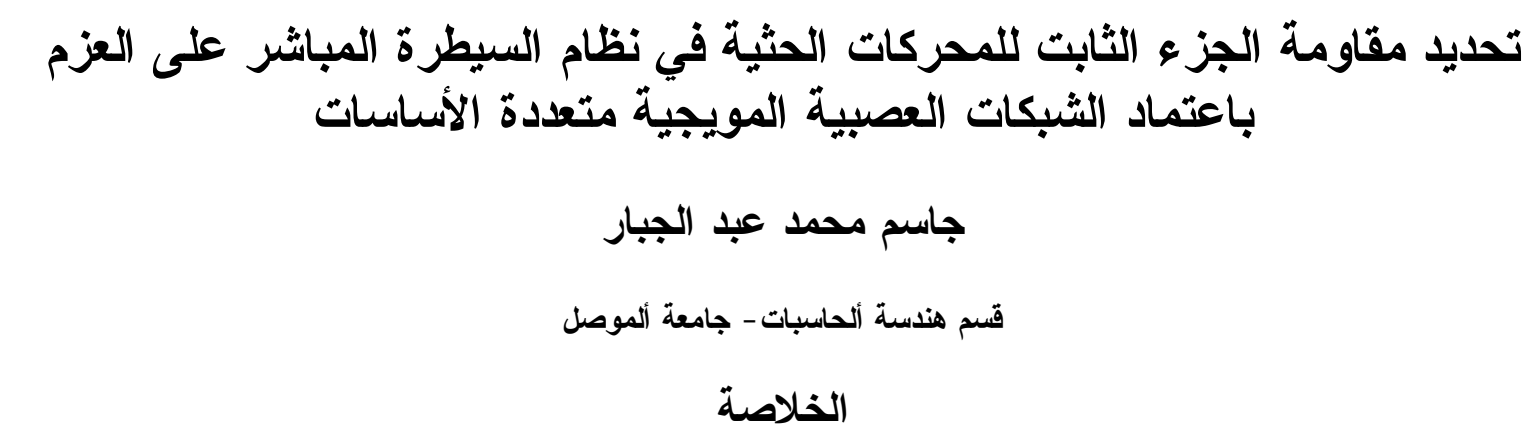

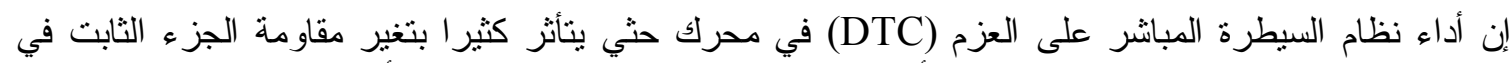

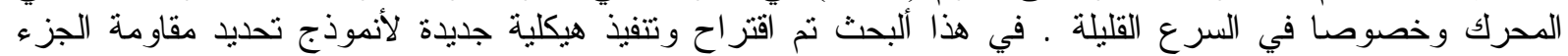

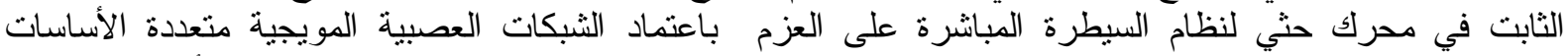

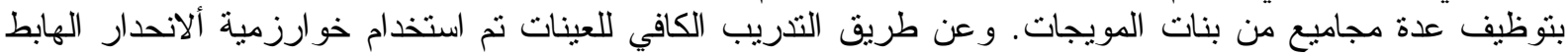

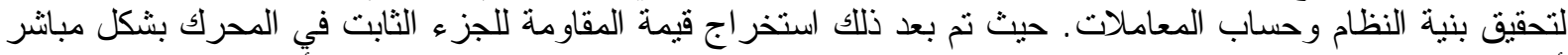

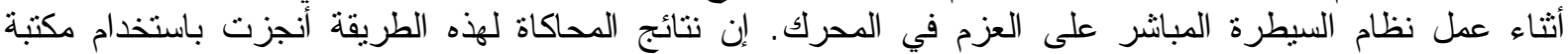

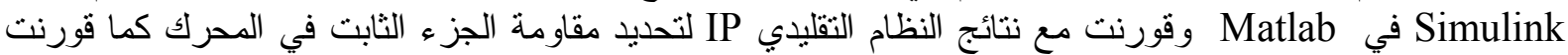
مع تقنية حديثة مبنية على الــwavenet .لقد أظهرت النتائج إمكانية الطريقة المقترحة على تحسين أداء النظام. 


\section{1- Introduction}

The industrial application areas of the DTC system have been increased recently due to several features such as quick torque response and robustness against the motor parameter variations [1]-[3]. The DTC system, shown in Fig.1, uses feedback control of developed torque and stator flux which are calculated in stationary $(d q)$ reference frame using measured stator voltages and currents. The calculation depends only on one machine parameter which is the stator resistance. The stator flux $\bar{\lambda}_{s}$ ( with magnitude $\left|\lambda_{s}\right|$ and angle $\theta_{s}$ ) and the developed torque $T_{e}$ are calculated according to the following equations [4]-[5].

$\bar{\lambda}_{s}=\int\left(\bar{v}_{s}-\bar{R}_{s} \bar{i}_{s}\right) d t$

$\bar{\lambda}_{s}$ can be represented in vector form as $\bar{\lambda}_{s}=\left[\lambda_{d s} \lambda_{q s}\right]^{T}$, while $\bar{v}_{s}=\left[\begin{array}{ll}v_{d s} & v_{q s}\end{array}\right]^{T}$ is stator voltage, $\bar{i}_{s}=\left[\begin{array}{lll}i_{d s} & i_{q s}\end{array}\right]^{T}$ is the stator current, and $\bar{R}_{s}=\left[\begin{array}{ll}R_{s} & 0 \\ 0 & R_{s}\end{array}\right]$ with $R_{s}$ as the stator resistance. Also

$\lambda_{d S}=\int\left(v_{d S}-R_{S} i_{d S}\right) d t$

and

$\lambda_{q S}=\int\left(v_{q S}-R_{S} i_{q s}\right) d t$

So,

$\left|\lambda_{s}\right|=\sqrt{\lambda_{d s}^{2}+\lambda_{q s}^{2}}$

and

$\theta_{s}=\tan ^{-1} \frac{\lambda_{q s}}{\lambda_{d s}}$

The developed torque $T_{e}$ is given by

$T_{e}=\frac{3}{2} P_{0}\left(\lambda_{a j} i_{q s}-\lambda_{p s} i_{i j}\right)$,

where $P_{O}$ is number of pole pairs.

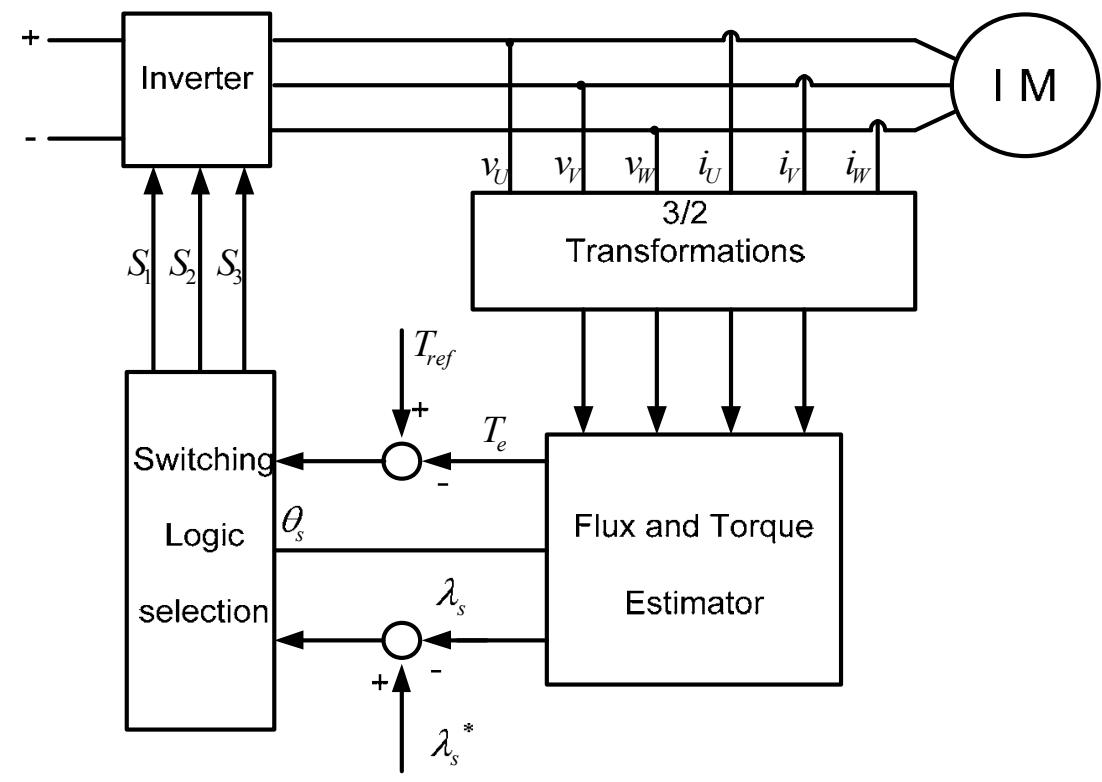

Fig. 1 Block diagram of DTC system. 
The effectiveness of the DTC controller using eqs. (1) - (4) depends upon the accuracy used to measure the stator resistance. The stator resistance varies with the operation conditions of the motor such as temperature and frequency variations. Particularly, at low speeds, the stator resistance voltage drop in eq. (1) is relatively large and may become comparable to the back electromotive force (emf). Any mismatch between the actual stator resistance value and the one used with DTC controller may lead not only to a substantial performance error but for instability [6]. Therefore, the accurate value of the stator resistance is of crucial importance for correct operation of the system and its identification then becomes necessary.

Several models have been proposed during the last decade to identify the stator resistance in DTC induction motor system. The nonlinear stator flux observer [7,8], real time PI estimator for identification stator resistance $[9,10]$, online fuzzy stator resistance observer $[11,12]$ and the stator resistance identifier based on artificial neural network (ANN) $[13,14]$.

The combination of ANN with wavelet transform (wavenet), preserves good localization property in both time and frequency domains with multi-scale characteristic. It is used for the analysis of non-stationary signals and learning of the nonlinear functions [15]. This technique is also proposed to identify the stator resistance in DTC system [16]. In this paper, the theory of wavenet is presented and a stator resistance identification model based on a multi-basis wavenet is proposed. The proposed method includes multi-set daughter wavelets from different mother functions in the hidden layer which is believed useful to represent functions containing different signal cutting, ripples and rapid signal changes. Two Simulink models of DTC induction motor system with stator resistance identifiers are implemented based on the proposed multi-basis wavenet and the classical PI control. Simulation results include developed torque, stator current and rotor speed with and without stator resistance identifiers. Note that the theory of DTC control is beyond the scope of this paper, however it can be found in details in [17]. Section 2 contains the wavenet fundamentals. A classical PI stator resistance identifier is considered in section 3. A proposed multi-basis wavenet stator resistance identifier is described in section 4 . Section 5 presents the simulation results of both PI and proposed multi-basis wavenet identifiers. A stiffness test of the proposed wavenet identifier is illustrated in section 6 . Finally, section 7 summaries some conclusions.

\section{2- Wavenet Fundamentals}

Wavenet can be considered a particular case of the feed forward basis function neural network model. In ordinary network, several types of basis functions, such as radial basis functions, splines and polynomial functions of synapse neurons are used instead of sigmodial function. The connection weights are taken to represent the corresponding coefficients. The output layer performs the sum of the output of all synapse neurons. Since wavelets have been shown their excellent performance in non stationary signal analysis and nonlinear function modeling, the neural network using wavelet basis function, wavenet, provides higher availability of rate of convergence for the approximation than an ordinary feed forward neural network [15].

The wavenet can be constructed by means of replacing the nonlinear sigmodial function with nonlinear wavelet basis function. Figure 2 illustrates the wavenet structure and Fig. 3 shows some typical wavelet functions. The structure of Fig. 2 exhibits a multi-input to multioutput nonlinear system, realizing an $R^{M} \Rightarrow R^{N}$ apping. 


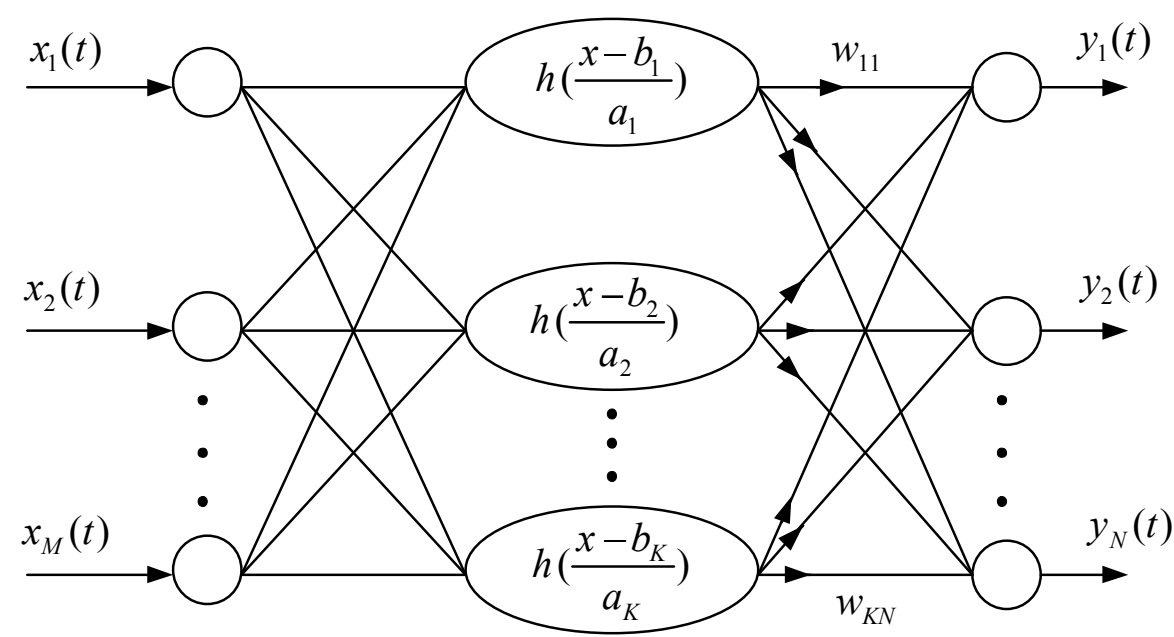
Input Layer of
Hidden Layer of $M$ source
$\mathrm{K}$ hidden Neuron

\section{Output layer of} $\mathrm{N}$ output

Fig. 2 The structure of wavenet, after [18]
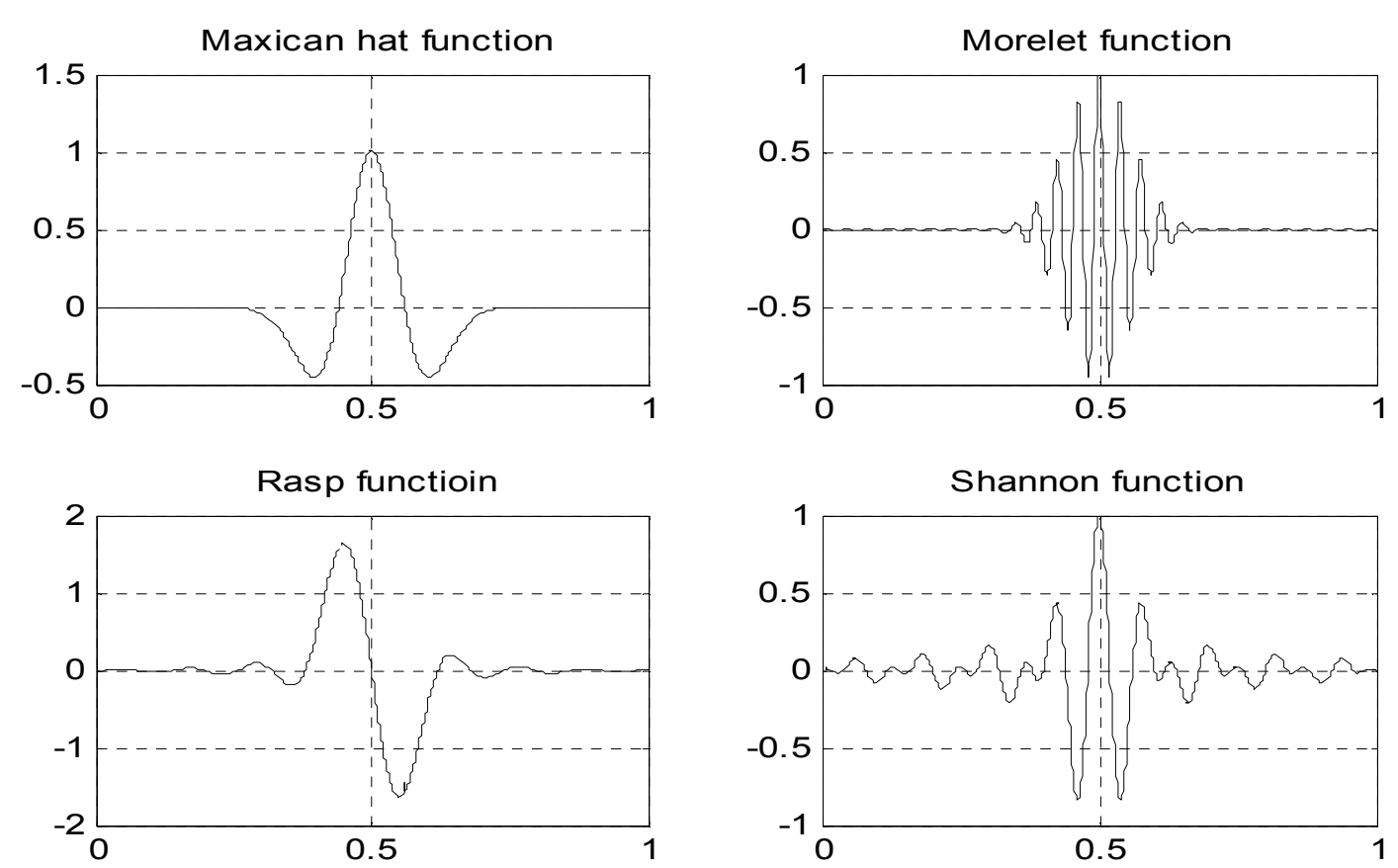

Fig. 3 Some typical wavelet functions

The approximated output signal of the network of Fig. 2 can be expressed as follows [18]:

$y_{i}=f\left[\sum_{k=1}^{K} w_{k i} \sum_{m=1}^{M} x_{m}(t) h_{m}\left(\left(x-b_{k}\right) / a_{k}\right)\right]$

where $x_{m}(m=1,2, \ldots, M)$ is the input for the $m^{\text {th }}$ training vector $X(t), \quad y_{i}(i=1,2, \ldots, N)$ is the output for the $i^{\text {th }}$ training vector $Y(t), M$ is number of nodes of the input layer, $K$ is number of nodes of hidden layer, $w_{k i}$ is the weight between the $k^{\text {th }}$ node of the hidden layer 
and the $i^{\text {th }}$ node of the output layer, $h(x)$ is the mother wavelet, $a_{k} \& b_{k}$ are the parameters of dilation and translation, respectively, and $f$ is the nonlinear function.

\section{3- Pi Stator Resistance Identifier}

The block diagram of the PI stator resistance tuner is shown in Fig. 4. The error $\left|\Delta \lambda_{s}(n)\right|$ between the magnitudes of the calculated stator flux linkage $\left|\lambda_{s}(n)\right|$ and its reference $\lambda_{s}{ }^{\bullet}$ is proportional to the stator resistance change. This error is used as an input to the PI identifier. The technique is based on the principle that the change in stator resistance will cause a change in the developed torque and magnitude of stator flux.

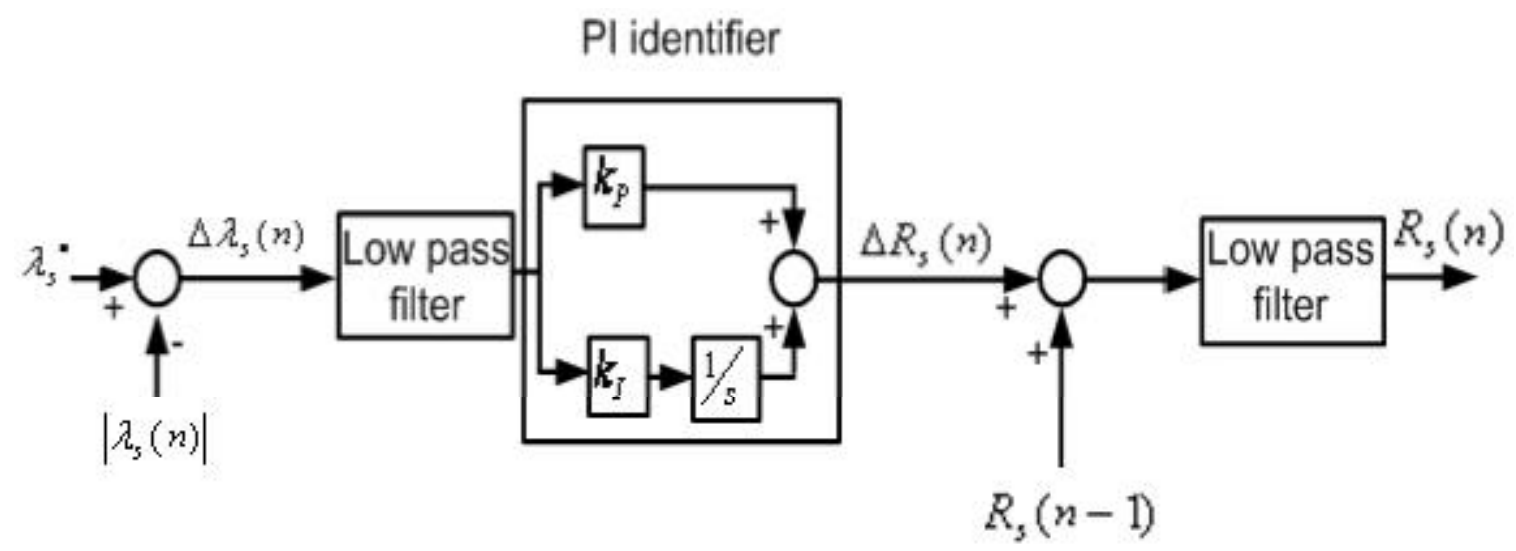

Fig. 4 PI stator resistance identifier, after [18]

The equation for PI resistance identifier is given by

$\Delta R_{s}(n)=\left(k_{P}+k_{I} \frac{1}{s}\right)\left|\Delta \lambda_{s}(n)\right|$

where $k_{p}$ and $k_{I}$ are the proportional and integral gains of the PI identifier. The error $\left|\Delta \lambda_{s}(n)\right|$ is passed through a low pass filter with a very low cutoff frequency in order to eliminate high frequency components contained in the magnitude of calculated stator flux. Then the signal is passed through a PI identifier. The output of the PI identifier represents the change in the stator resistance $\Delta \mathbb{R}_{s}(n)$ due to change in motor stator resistance. The change $\Delta R_{s}(n)$ is continuously added to the previously identified stator resistance $R_{s}(n-1)$. The identified resistance is again passed through a low pass filter to have a smooth variation of stator resistance final value $R_{s}(n)$. The identified resistance is used directly in the DTC controller.

\section{4- Proposed Stator Resistance Identifier}

The structure of the proposed $P$-basis wavenet stator resistance identifier is shown in Fig. 5 and the set up for its training and identification for stator resistance changes is shown in Fig. 6 The wavenet identifier exhibits two inputs and single output. The input nodes are the stator flux error and the change in the stator flux error $\Delta \in(n)$. They are defined as follows:

$$
\begin{aligned}
& e(n)=\left|\Delta \lambda_{3}(n)\right|=\left|\lambda_{3}+\right|-\left|\lambda_{3}(n)\right| \\
& \Delta e(n)=e(n)-e(n-1)
\end{aligned}
$$


where $\left|\lambda_{s} \cdot\right|$ is the stator flux command and $\left|\lambda_{s}(n)\right|$ is the calculated the stator flux. The stator flux command can be determined using simulations for conventional DTC system. Its value depends implicitly on the demand torque and rotor speed. The hidden layer is of $P$ different

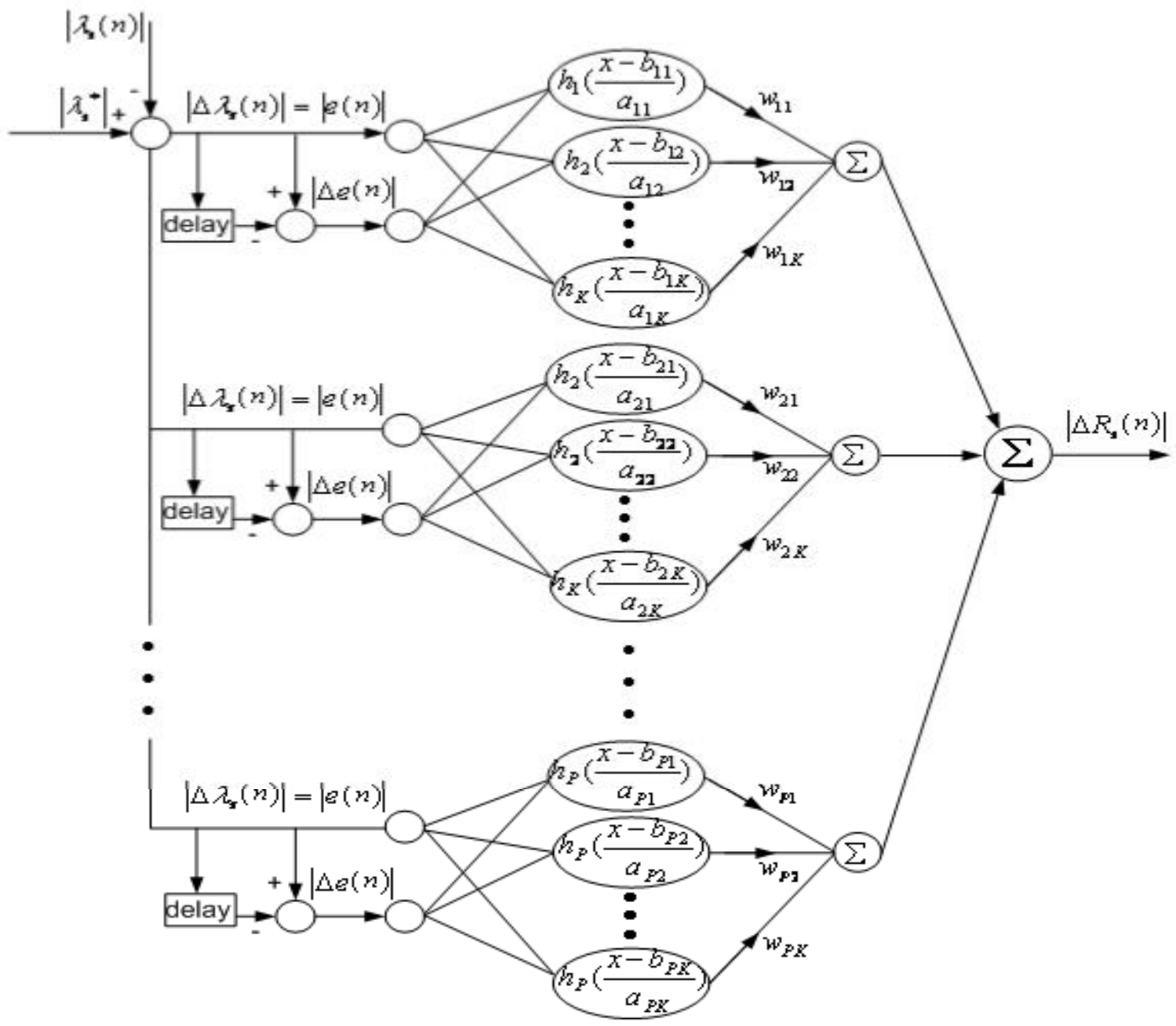

Fig. 5 The proposed 2-input / single output $P$-basis (each of $K$ daughters) wavenet stator resistance identifier.

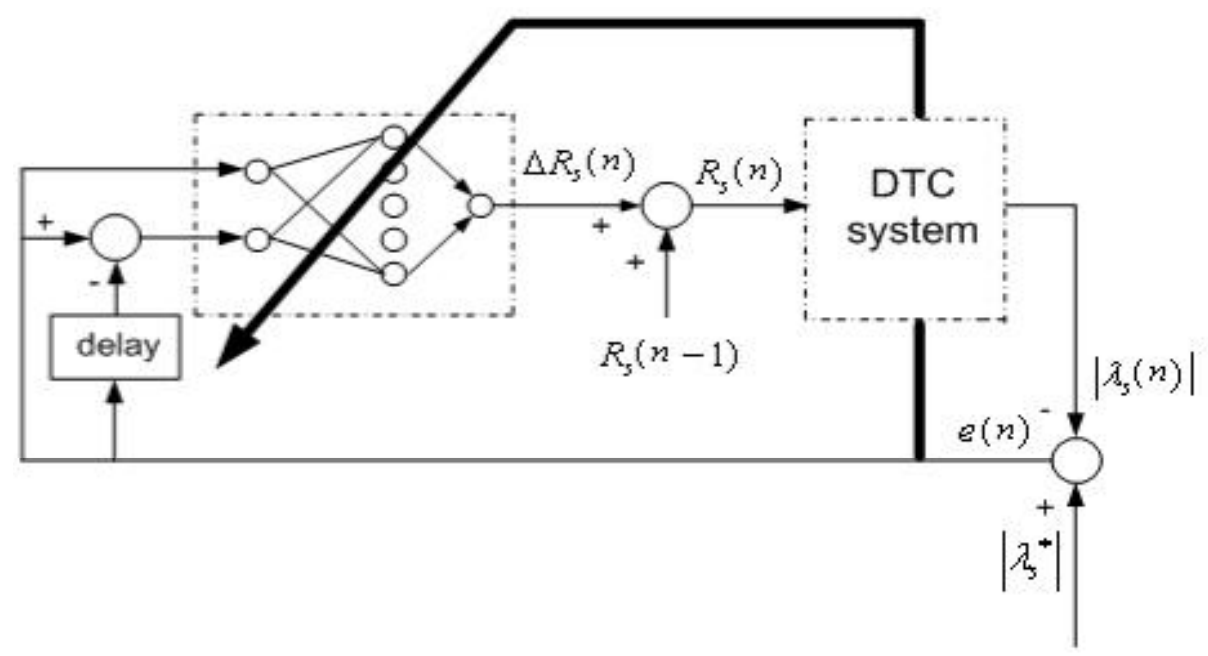

Fig. 6 The set up for online training and identification of stator resistance. 
sets of daughter wavelets. The output $y$ of such wavenet is the stator resistance change $\Delta R_{5}(n)$ which is added to the previous value to give the identified stator resistance according to the following equations:

$$
\begin{aligned}
& y=\Delta R_{s}(n)=f\left[\sum_{p=1}^{P} \sum_{k=1}^{X} w_{p k} \sum_{m=1}^{M} X_{m} h_{p}\left\{\left(x-b_{p k}\right) / a_{p k}\right\}\right] \\
& R_{s}(n)=R_{g}(n-1)+\Delta R_{s}(n)
\end{aligned}
$$

In order to determine the adjustable weighs $w_{m}(p=1,2, \ldots P, k=1,2, \ldots K$ where $P$ is number of different used mother wavelet functions and $K$ is number of used daughter functions) and the adjustable parameters $a_{p k}$ and $b_{p k}$, a similar algorithm to that given in [19] is followed. A least mean square (LMS) energy minimizing function of the following form can be applied:

$$
E=\frac{1}{2} \sum_{l=1}^{q} \sum_{i=1}^{n}\left[e^{l}(n)\right]^{2}
$$

where $e^{l}(n)=y_{d}^{L}-y^{l}, q$ is the number of training samples and $y_{d}^{l}$ s the desired value of $y^{l}$. To minimize the energy error $E$, a method of steepest descent which requires the gradients $\frac{\partial E}{\partial w_{p k}}, \frac{\partial E}{\partial a_{p k}}$ and $\frac{\partial E}{\partial b_{p k}}$ is used for updating the incremental changes to each parameter $w_{p k}, a_{p k}$, and $b_{p k}$. Different gradients of $E$ at iteration $n$ are given by

$$
\begin{aligned}
\frac{\partial E}{\partial w_{p k}} & =-\sum_{l=1}^{q} \sum_{i=1}^{N} \sum_{m=1}^{M} e^{l}(n) X_{m}{ }^{l} h(\tau) \\
\frac{\partial E}{\partial b_{p k}} & =-\sum_{l=1}^{q} \sum_{i=1}^{N} \sum_{m=1}^{M} e^{l}(n) X_{m}{ }^{l} * w_{p k} \frac{\partial h(\tau)}{\partial b_{p k}} \\
\frac{\partial E}{\partial b_{p k}} & =-\sum_{l=1}^{q} \sum_{i=1}^{N} \sum_{m=1}^{M} e^{l}(n) X_{m}{ }^{l} * w_{p k} \tau \frac{\partial h(\tau)}{\partial b_{p k}}=\tau \frac{\partial E}{\partial b_{p k}}
\end{aligned}
$$

where $\tau=\frac{x-b_{p k}}{a_{p k}}$. The weighs $w_{p k}$ and the parameters $a_{p k}$ and $b_{p k}$ are, respectively, updated as

$$
\begin{aligned}
& w_{p k}(n+1)=w_{p k}(n)-h_{w} \frac{\partial E}{\partial w_{p k}}+c_{w} \Delta w_{p k}(n) \\
& a_{p k}(n+1)=a_{p k}(n)-h_{a} \frac{\partial E}{\partial a_{k}}+c_{a} \Delta a_{p k}(n) \\
& b_{p k}(n+1)=b_{p k}(n)-h_{b} \frac{\partial E}{\partial b_{k}}+c_{b} \Delta b_{p k}(n)
\end{aligned}
$$

where $h_{w}, h_{a}$, and $h_{b}$ are steps size, $c_{w}, c_{2}$ and $c_{b}$ are the forgetting factors which are variable factors and can greatly reduce the number of iterations for convergence.

\section{5- Simulation Results}

Two sets of daughter wavelet functions $(P=2)$ with seven neurons $(K=7)$ in each set are used to represent the hidden layer of a 2-basis wavenet stator resistance identifier. The two mother wavelets used in these sets are Mexican hat and Shannon functions. These functions 
with their derivatives w. r. to the translation $b$ are given as follows: For Mexican hat function

$$
\begin{aligned}
& h(t)=\frac{2}{\sqrt{3}} \pi^{\frac{1}{4}}\left(1-\frac{2}{t}\right) e^{-\frac{t^{2}}{a}} \\
& \frac{\partial h(t)}{\partial b}=\frac{1}{a}\left(3 t-t^{3}\right) e^{-\frac{t^{2}}{2}}
\end{aligned}
$$

and for Shannon function

$$
\begin{aligned}
& h(\tau)=\frac{\sin 2 \pi \tau-\sin \pi \tau}{\pi \tau} \\
& \frac{\partial h(\tau)}{\partial b}=\frac{\pi}{a} \frac{(-\pi \tau \cos \pi \tau-2 \pi \cos 2 \pi \tau+\sin \pi \tau+\sin 2 \pi \tau}{(\pi \tau)^{2}}
\end{aligned}
$$

The simulation is carried out to verify the function of the stator resistance identifier where the motor used in this system is $1250 \mathrm{hp}, 4160 \mathrm{~V}, 150 \mathrm{~A}, 6$ poles and $60 \mathrm{~Hz}$. The simulation parameters of the motor are described as follows: rated speed $N_{s}=1200$ r.p.m., stator resistance $R_{s}=0.21 \Omega$, rotor resistance $R_{r}=0.146 \Omega$, stator ( rotor ) leakage inductance $L_{s}=L_{r}=5.2 \mathrm{mH}$, magnetizing inductance $L_{m}=0.155 \mathrm{H}$ and moment of inertia $J=22 \mathrm{~kg} \cdot \mathrm{m}^{2}$. The stator flux command, used as input to the PI or wavenet stator resistance identifier, is determined from a conventional DTC operation characteristic (see Fig. 7) which relates the stator flux linkage to the torque reference for different speed references. Simulations are determined using full load torque and 300 r.p.m speed reference in Fig. 7. Thus, the stator flux command will be $8.943 \mathrm{~Wb}$. The simulink model of DTC induction motor system with wavenet stator resistance identifier is shown in Fig. 8. The stator resistance of the motor is taken from a certain pattern, while the stator resistance used in the DTC controller is taken either from constant value referred to its rated value or from the PI or the proposed identifier.

Figure 9 shows the curves of stator resistance pattern, developed torque, stator current and rotor speed without stator resistance identifier. The stator resistance $R_{s}$ pattern in

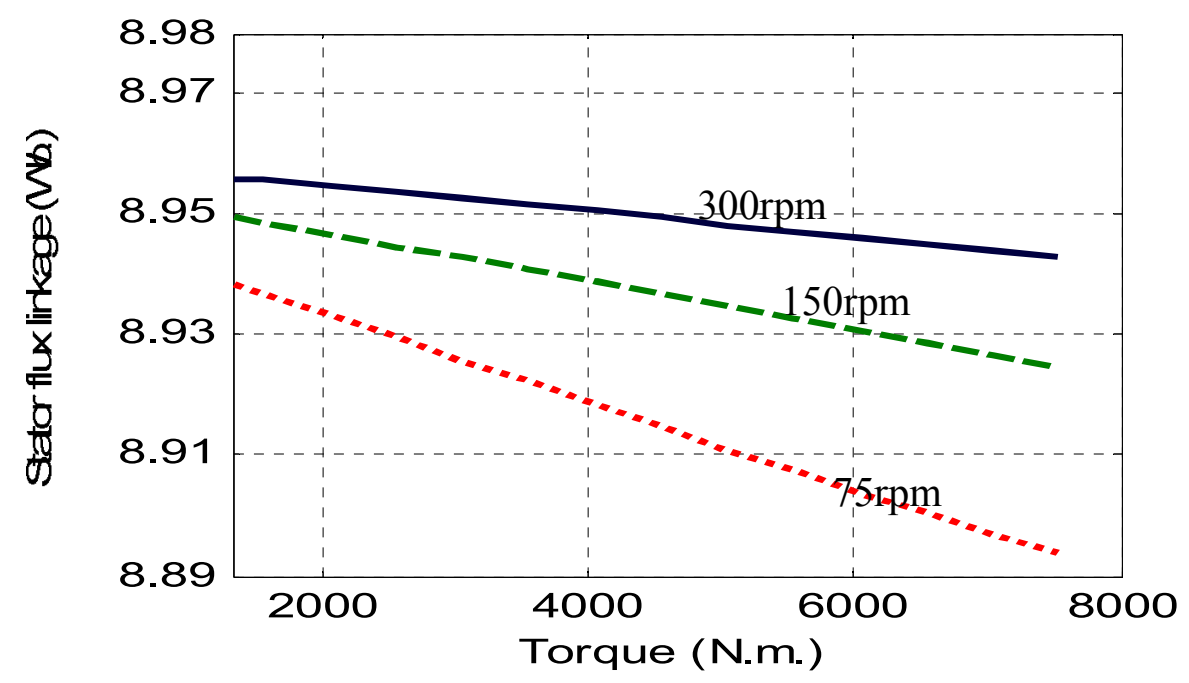

Fig. 7 Stator flux-torque relation. 


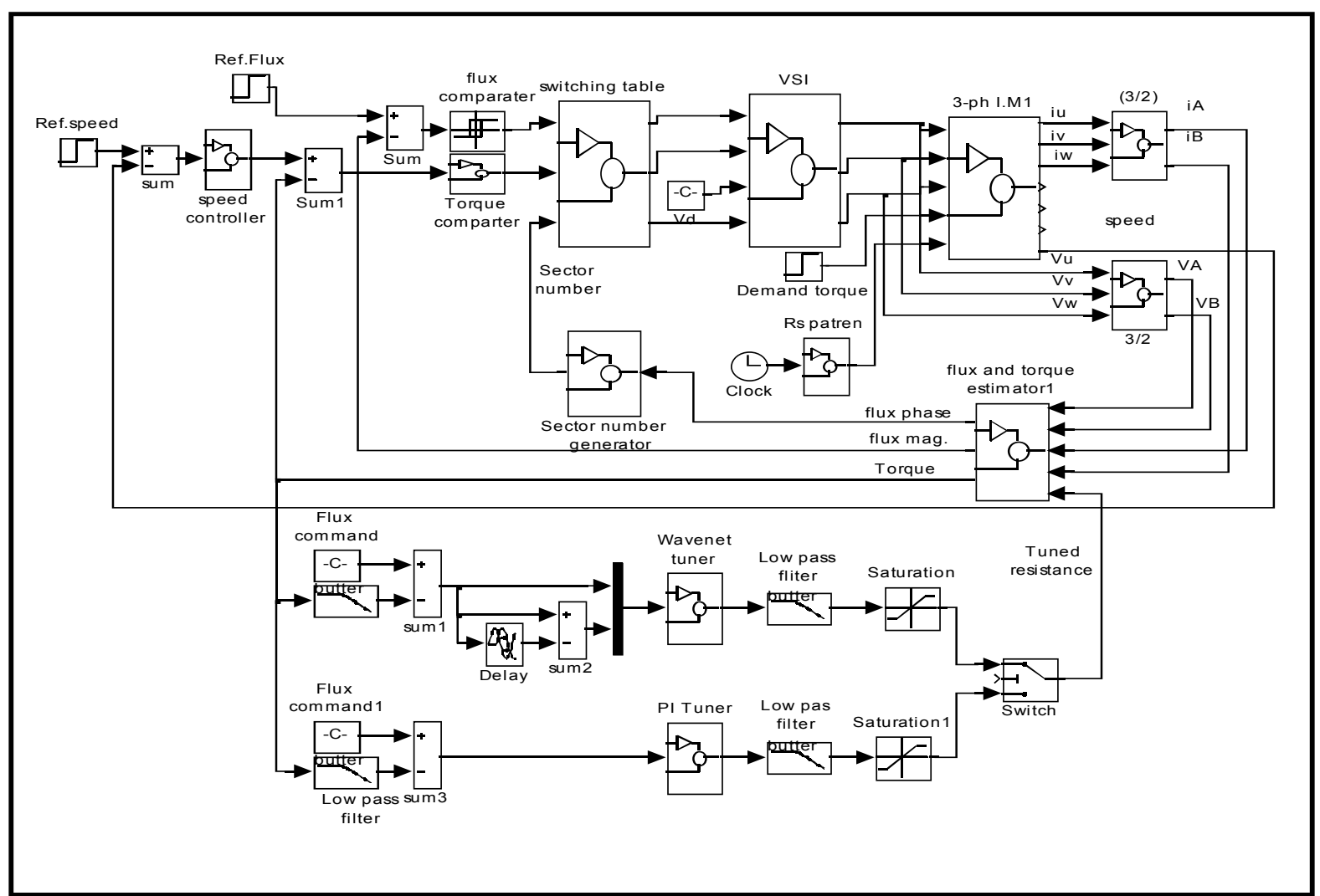

Fig. 8 A simulink model of DTC induction motor system.

Fig. 9(a) is used to train the wavenet off line before combing it with the DTC system. This pattern starts at rated stator resistance of $0.21 \Omega$ and keeps constant for 4 secs, then increases to 150 percent of its rated value at an approximate rate of $0.013 \Omega / \mathrm{sec}$. Then it remains constant for another 4 secs. The developed torque, the stator current and the rotor speed are shown in Fig. 9 (b-d). These plots show the effect of stator resistance change under conventional DTC system. The developed torque varies nonlinearly and has 4 percent error due to the change given in stator resistance. The stator current and the rotor speed are also changed nonlinearly and have 2.5 percent and 9 percent error for the same change in the stator resistance respectively. From these plots, it can be concluded that, the torque control is highly affected by stator resistance variations. Therefore, it is extremely necessary to implement some stator resistance identification to preserve torque control.

Figures 10 and 11 show the same previous curves with PI and multi-basis wavenet stator resistance identifiers, respectively. In both figures, the identified stator resistance follows closely its pattern(much closer in the case of multi-basis wavenet identifier) resulting in reducing the error in the developed torque, stator current and rotor speed. So, the wavenet stator resistance identifier is able to identify the resistance change better than PI identifier, for example the error in developed torque is reduced to 0.7 percent by using PI identifier while with wavenet identifier the developed torque stays approximately constant all the time.

\section{6- Stiffness Test Of Proposed Wavenet Identifier}

The proposed multi-basis wavenet stator resistance identifier is tested here with a hard stator resistance pattern to ensure its ability to compensate the effects of stator resistance variations in practical DTC system. The maximum variation in stator resistance in practical case is around 180 percent of its rated value [6]. Thus, the following stator resistance pattern, including such variations, will be examined. Such pattern, shown in Fig. 12(a), starts at a 


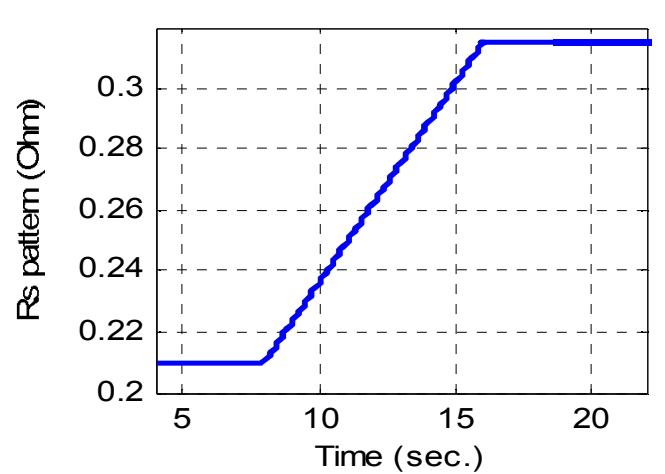

(a)

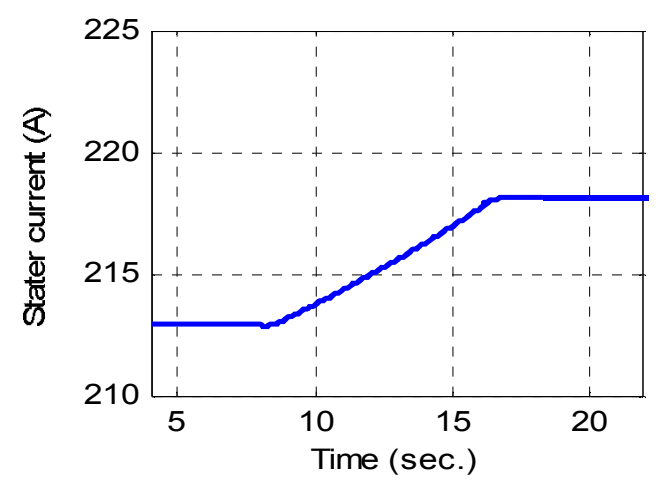

(c)

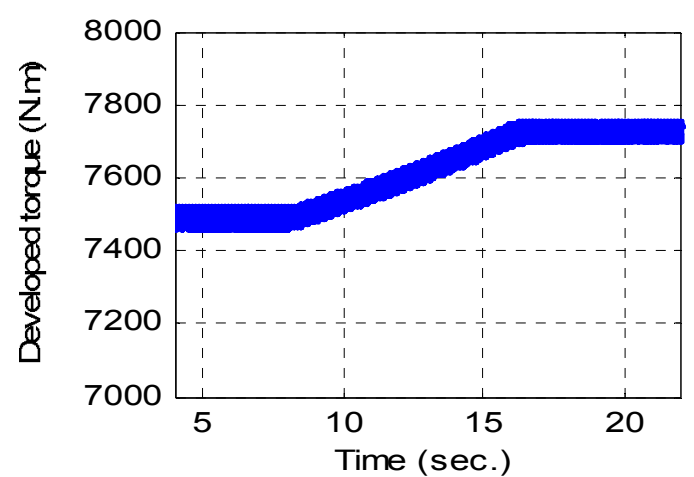

(b)

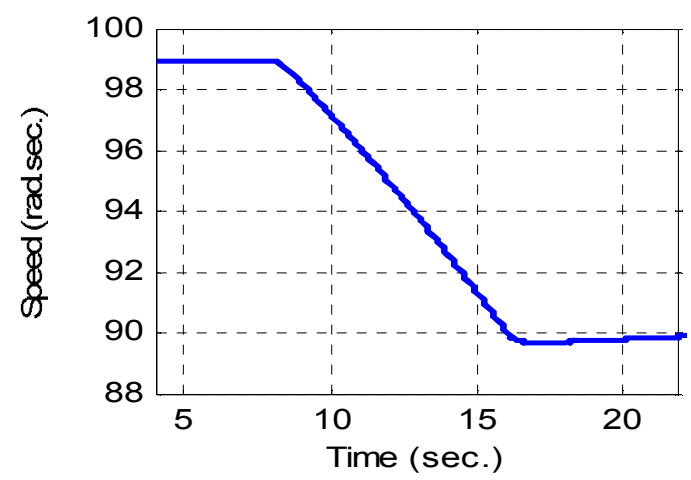

(d)

Fig. 9. The curves without stator resistance identification

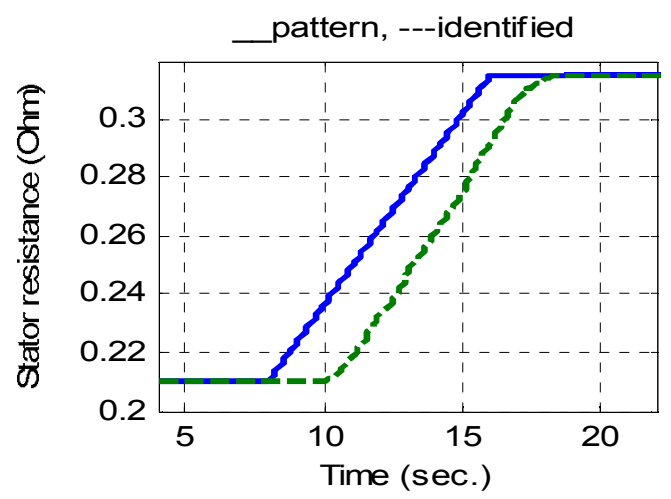

(a)

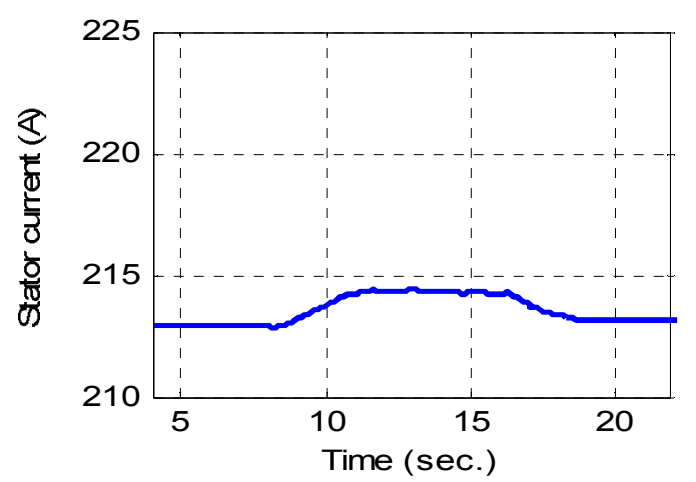

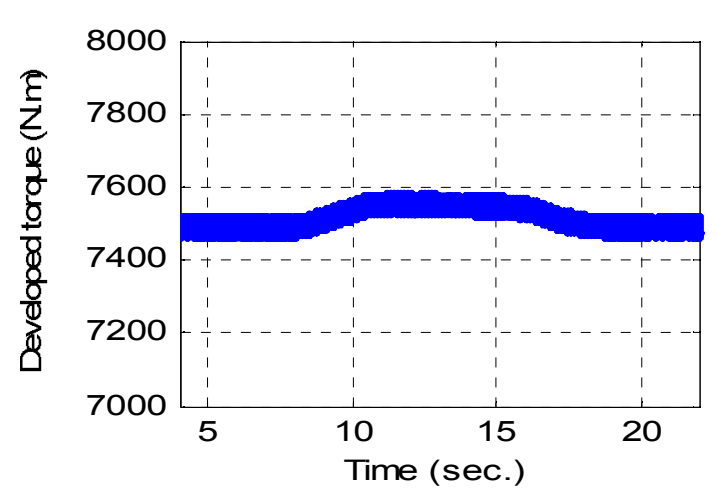

(b)

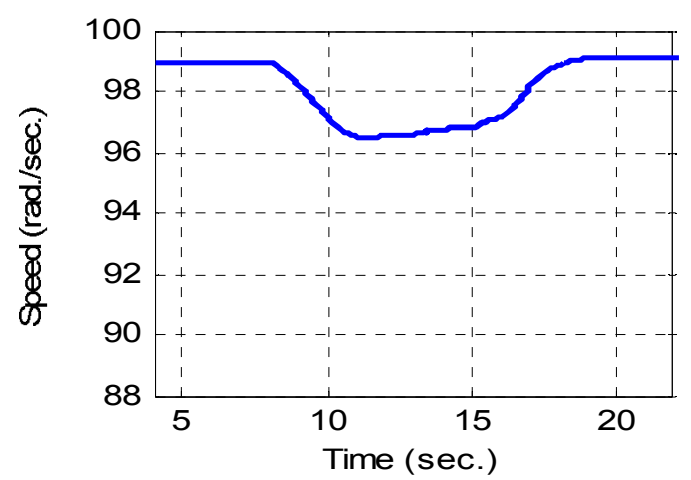

Fig. 10. The curves with PI stator resistance identifier. 


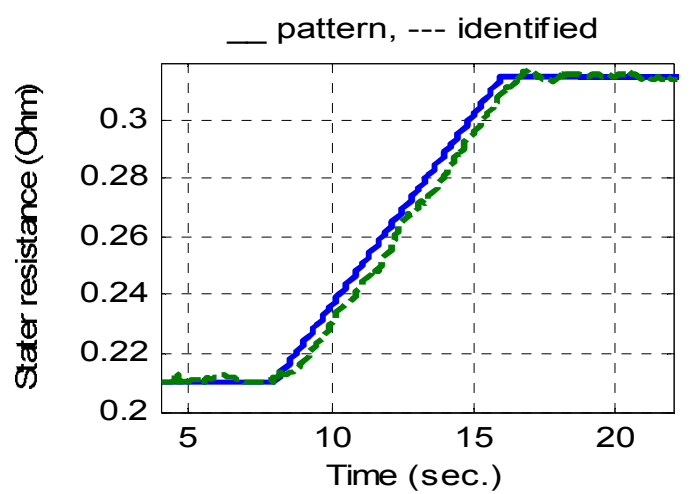

(a)

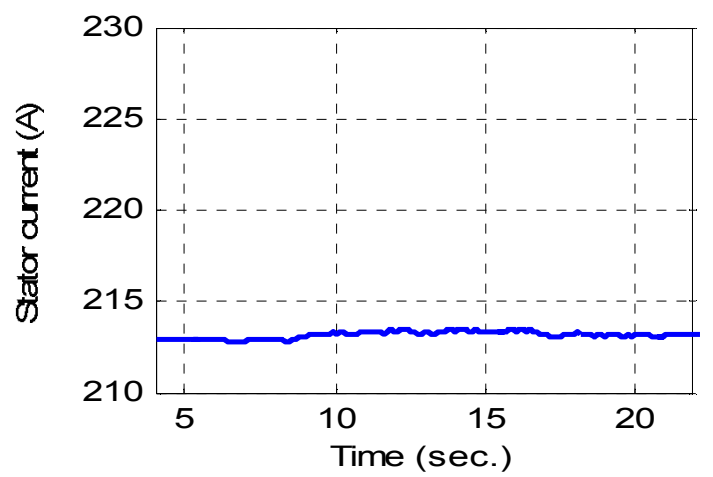

(c)

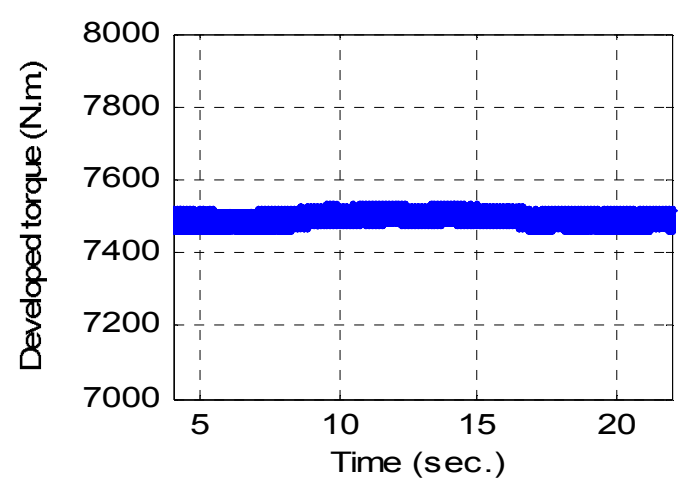

(b)

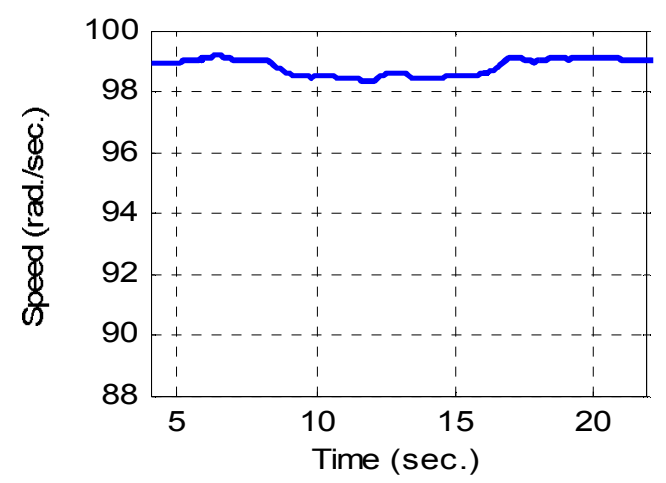

(d)

Fig. 11 The curves with multi-basis wavenet stator resistance identifier.

rated value of $0.21 \Omega$ and keeps constant for 4 secs, then increases linearly up to 1.8 times rated value during 4 secs and remains constant for another 2 secs. After that, it decreases linearly to its rated value during 4 secs with the same magnitude of rate change and stay constant at this value for 2 secs. This process is repeated three times. The simulation results are shown in Figs. 12 and 13. Figures 12(b-d) show the resulting curves of developed torque, the stator current and the rotor speed, without stator resistance identification. Figure 13(a) shows the curves of the original pattern and the identified one, with the proposed multi-basis wavenet stator resistance identifier. Figures 13(b-d) show the resulting curves of the developed torque, the stator current and the rotor speed, with the proposed multi-basis wavenet stator resistance identifier. Comparing the corresponding curves in Figs.12 and 13, it can be seen that the variations in the levels of the developed torque, the stator current and the rotor speed are highly reduced with the use of the proposed identifier. For the sake of comparison, Table 1 illustrates the values of maximum errors in the developed torque, the stator current and the rotor speed under the mentioned stator resistance pattern, for PI, wavenet of [18] and the proposed multi-basis wavenet stator resistance identifiers. Such table indicates the ability of the proposed identifier to compensate the effect of stator resistance variations thus, improving the DTC system performance. 


\section{Al-Rafidain Engineering $\quad$ Vol.18 $\quad$ No.2 $\quad$ April 2010}

\section{7- Conclusions}

In this paper, a new multi-basis wavenet stator resistance identifier based on multi-set daughter wavelets functions has been proposed to compensate the effect of stator resistance variations in DTC induction motor system operating at low speed. The multi-basis wavenet is useful because of the high nonlinearity in the stator current and flux waveforms. The proposed wavenet is trained (off line) before combining it with the DTC system and its parameters are optimized using steepest gradient algorithm. The results of simulations show that the proposed identifier has the ability to realize on line identification of stator resistance better than both; classical PI and recent wavenet identifiers. So, with the proposed identifier, the performance of the DTC system has been improved.

Table 1: Maximum error comparison.

\begin{tabular}{|c|c|c|c|}
\hline $\begin{array}{c}\text { Max. error in } \\
\text { rotor speed } \\
\text { (rad./sec.) }\end{array}$ & $\begin{array}{c}\text { Max. error in } \\
\text { stator current (A) }\end{array}$ & $\begin{array}{c}\text { Max. error in } \\
\text { torque (N.m) }\end{array}$ & Type of Identifier \\
\hline 9 & 5.2 & 206 & PI \\
\hline 3.2 & 2.6 & 70 & Wavenet of [18] \\
\hline 2.5 & 2 & 65 & $\begin{array}{c}\text { The proposed multi- } \\
\text { basis wavenet }\end{array}$ \\
\hline
\end{tabular}

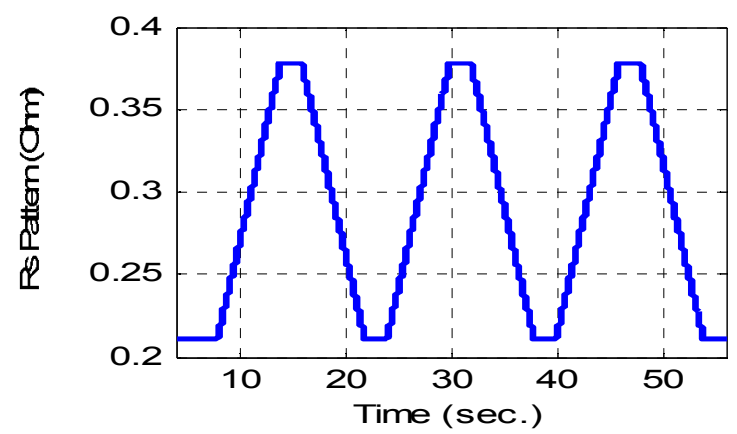

(a)

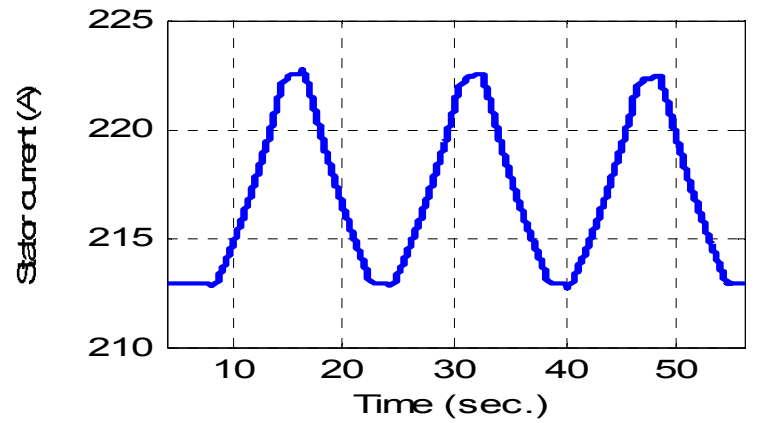

(c)

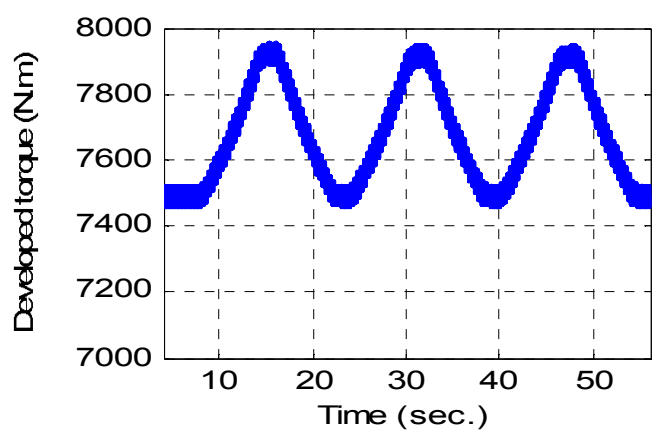

(b)

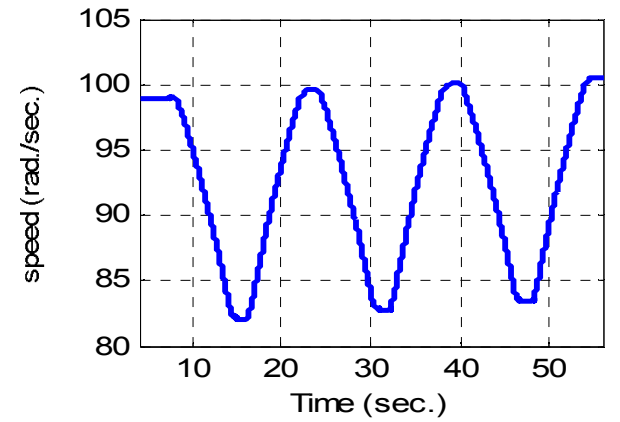

(d)

Fig. 12 The curves without stator resistance identifier. 


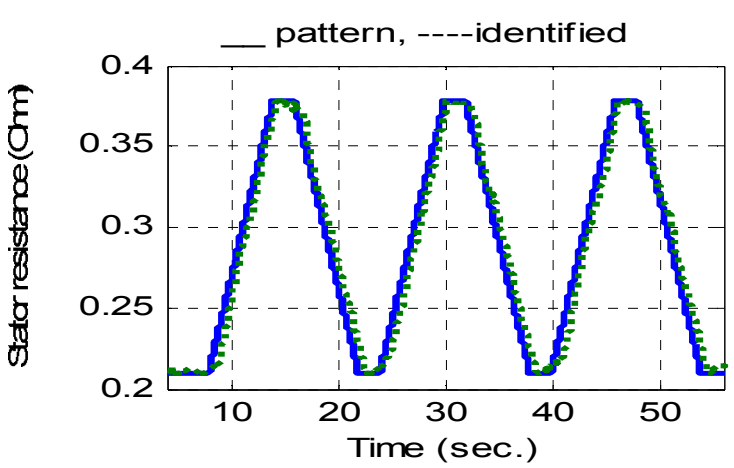

(a)

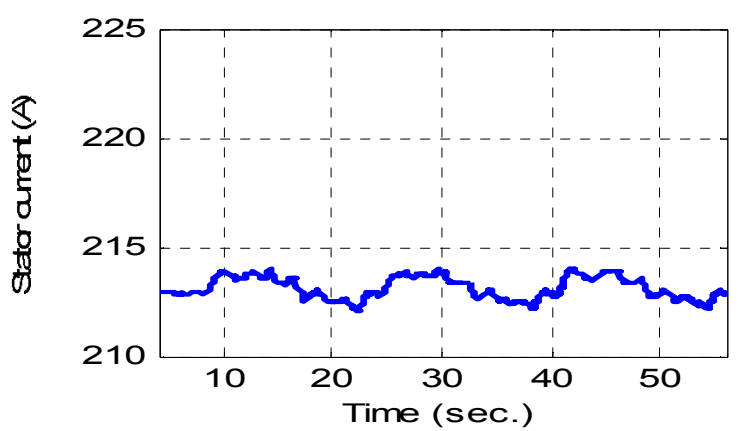

(c)

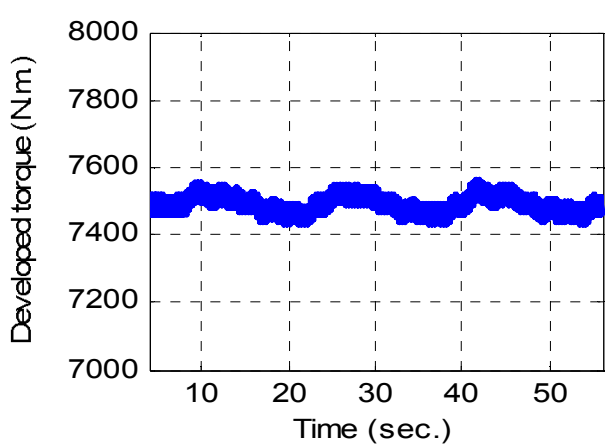

(b)

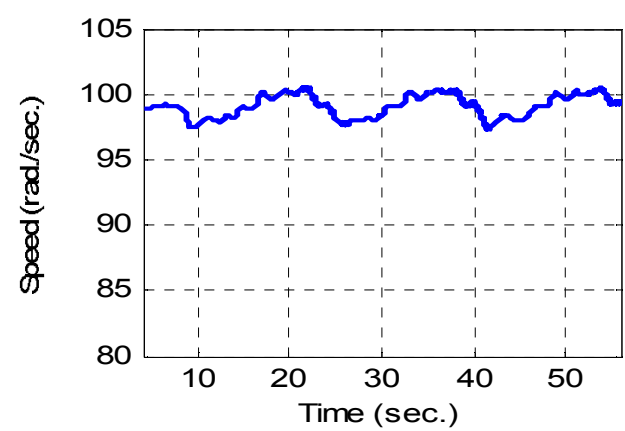

(d)

Fig. 13 The curves with wavenet stator resistance identifier.

\section{References}

[1] I. Takahashi and T. Noguchi, "A New Quick-Response and High Efficiency Control Strategy of an Induction Machine", IEEE Trans. Ind. Applicat., Vol. IA-22, No. 5, pp. 820-827, Sep./Oct. 1986.

[2] R. Toufouti, S. Meziane and Benalla, "Direct Torque Control Strategy of Induction Motors", Acta Electrotechnica et Informatica, Vol. 7, No.1, pp. 1-7, 2007.

[3] H. F. Abdul Wahab and H. Sanusi, "Simulink Model of Direct Torque Control of Induction Machines", American Journal of Applied Sciences, Vol. 5, No. 8 pp. 1083-1090, 2008.

[4] B. K. Bose, Modern Power Electronics and AC Drives, Prentice Hall PTR, ISBN 0-13016743-6, 2001.

[5] Bin Wu, High power Converters and AC Drives, Wiley-IEEE Press, ISBN 978-0-471-731719, 2006.

[6] Z. Huang, W. Gui, X. Nian, X. Liu and Y. Shan. "A Novel Stator Resistance Identification for Speed Sensorless Induction Motor Drives Using Observer", IEEE ISIE, pp. 2211-2216, July 9-12, 2006.

[7] Y. O. Choi, K. Y. Lee, K. S. Seo, G. B. Kim, and B. H. Jung, "Performance Analysis of the DTC Using a Closed Loop Stator Flux Observer for Induction Motor in the Low Speed Range", $5^{\text {th }}$ International conference on Electrical Machines and Systems, ICEMS, Vol.1, pp. 89-93. Aug. 2001. 


\section{Al-Rafidain Engineering $\quad$ Vol.18 $\quad$ No.2 $\quad$ April 2010}

[8] J. Soltani, G. R. Arab Markadeh and S. H. Hosseiny, "A New Adaptive Direct Torque Control (DTC) Scheme Based-on SVM for Adjustable Speed Sensorless Induction Motor Drive", $30^{\text {th }}$ Annual Conference on the IEEE Electronic Society, pp. 1111-1116, Nov. 2-6, 2004.

[9] B. S. Lee and R. Krishnan, "Adaptive Stator Resistance Compensator for High Performance Direct Torque Controlled Induction Motor Drives", $33^{\text {rd }}$ Industry Applications Conference, Annual Meeting, IEEE, Vol. 1, pp. 423430, 12-15 Oct. 1998.

[10] S. Haghbin, M. R. Zolghadri, S. Kaboli and A. Emadi, "Performance of PI Stator Resistance Compensator on DTC of Induction Motor", $29^{\text {th }}$ Annual Conference of the IEEE, Industrial Electronics Society IECON'03, Vol. 1, pp. 425-430, 2-6 Nov. 2003.

[11] L. Zhong, M. F. Rahman, K. W. Lim, Y. W. Hu, and Y. Xu. " A Fuzzy Observer for Induction Motor Stator Resistance for Application in Direct Torque Control", 1997 International Conference on Power Electronics and Drive Systems, Vol. 1, 26-29 May 1997.

[12] F. Zidani, D. Diallo, M. E. H. Benhouzid, and R. Nait-Said, "Direct Torque Control of Induction Motor With Fuzzy Stator Resistance Adaptation", IEEE Trans. On Energy Conversion, Vol. 21, No. 2, pp. 619-621, July 2006.

[13] L. A. Cabera, M. E. Elbuluk and I. Husain, "Tuning the Stator Resistance of Induction Motors Using Artificial Neural Network", IEEE Trans. On Power Electronics, Vol. 12, No. 5, pp. 779-787, Sep. 1997.

[14] B. Karanayil, M. F. Rahman, and C. Grantham, "Online Stator and Rotor Resistance Estimation Scheme Using Artificial Neural Networks for Vector Controlled Speed Sensorless Induction Motor Drive", IEEE Trans. On Industry. Electron. Vol. 54, No. 1, pp. 167-176, Feb. 2007.

[15] S. Mallat, A Wavelet Tour of Signal Processing, Academic Press, ISBN 012466606X, 1999.

[16] C. Z. Cao, M. P. Lu, Q. D. Zhang, and Y. C. Zhang, "Research Online Identification of the Stator Resistance Using Wavelet Neural Network", $3^{\text {rd }}$ International Conference on Machine Learning and Cybernetics, pp. 3073-3077, 26-29 August 2004.

[17] G. S. Buja and M. P. Kazmierkowski, "Direct Torque Control of PWM Inverter-Fed AC Motors-A Survey", IEEE Trans. Ind. Electron., Vol. 51, No. 4, pp. 744-757, Aug. 2004.

[18] A. A. Obed, " Speed Estimation and Stator Resistance Tuning in DTC Drive Based on Wavenet Theory ", Ph.D. Thesis, Electrical Engineering Dept., College of Engineering, University of Basrah, September 2008.

[19] G. Lekutai , “Adaptive Self-Tuning Neuro Wavelet Network Controllers”, Ph.D. thesis, Virginia Polytechnic Institute, Blacksburg, Virginia, 1997. 